\title{
Design and Computational Studies on Plain Flaps
}

\author{
M. Senthil Kumar and K. Naveen Kumar
}

\begin{abstract}
In this paper, Computational fluid Dynamics (CFD) is used to predict accurately the incremental lift due to use of passive lift-augmentation device 'Flap'. In a 2-D wing, lift at a given angle of attack can be increased by increasing camber. In aircraft design, values of Maximum Lift Coefficient $\left(C_{L} \max \right)$ are used to determine the take-off and landing distances, on the assumption of usage of some type of lift- enhancing device. Passive lift enhancement device, such as a trailing edge plain flap, is relevant to most of the aircraft designs except Short Take Off and Landing (STOL) However, accurate analytical solutions to complex non linear equations of aerodynamics are a far cry and one has to depend largely on support from experimental results. It is here that CFD analysis makes the task simpler. Computational study of a typical plain flap with NACA (National Advisory Committee for Aeronautics) 0012 airfoil is taken up to predict its influence on incrementing the lift during critical phases of flight at low speed. The flow analysis is done using CFD tool FLUENT 6.3 along with GAMBIT 2.2. Effect of Plain flaps on basic aerodynamic parameters such as $C_{P}, C_{L}, C_{D}$ are studied by analyzing the flow over an airfoil with plain flap. The results obtained from the analysis are compared with analytical solutions to establish the influence and relevance of flap as an effective high lift device.
\end{abstract}

Keywords---- Aerodynamic Parameters, Computational Fluid Dynamics, High Lift Devices, NACA 0012 Airfoil, Plain Flaps

\section{NOMENCLATURE}

CFD - Computational fluid Dynamics

$\mathrm{C}_{\mathrm{L} \max } \quad$-Maximum Lift Coefficient

STOL -Short Take Off and Landing

NACA - National Advisory Committee for Aeronautics

$\mathrm{C}_{\mathrm{P}} \quad$-Pressure Coefficient

$\mathrm{C}_{\mathrm{L}} \quad$-Lift Coefficient

$\mathrm{C}_{D} \quad$.Drag Coefficient

AOA ( $\boldsymbol{\alpha})$-Angle of Attack

M. Senthil Kumar, Assistant Professor (SRG), Department of Aeronautical Engineering, Kumaraguru College of Technology, Coimbatore, Tamil Nadu-India.E-mail:mgskumar_pec@yahoo.com

K. Naveen Kumar Assistant Professor, Department of Aeronautical Engineering, Kumaraguru College of Technology-Coimbatore, Tamil NaduIndia.E-mail:naveenaero.1@gmail.com $\delta \quad$-Deflection angle

$\Delta \mathrm{C}_{L} \quad$ - Increment in Lift Coefficient

\section{INTRODUCTION}

$\mathrm{P}$ ROHIBITIVE fuel costs have mandated that the designer of a modern airliner optimizes his design for transonic cruise. This, obviously, would result in a sub-optimal design for the phases of low speed flight. It is usually not enough to optimize one single airfoil shape. The need arises for conformal changes of the airfoil to achieve best performance in both conditions. This is where high lift devices enter the design space. Therefore, study and analysis of high devices play a dominant role in design.

The rear portion of airfoil in the plain flap rotates downwards on a simple hinge mounted at the front of the flap to enhance the lift characteristics. A form of wing flap in which a portion of the trailing edge of the wing folds down to increase the camber of the wing without increasing the wing area.[3]

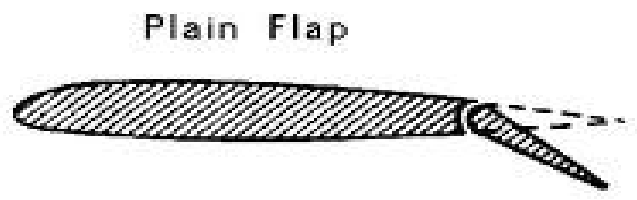

Aircraft design maximizes performance for a particular role and sub optimal for other roles; this deficiency is later compensated by introducing temporary remedial measures. One of the most critical areas affected is the size of the winga larger wing will provide more lift and reduce the minimum distances needed for takeoff and landing but the same arrangement will increase drag during cruising flight and thereby lead to less - than optimum fuel economy. High-lift devices are used as a go-between the two goals, allowing the use of an efficient cruising wing while, at the same time, adding lift for takeoff and landing [8] and [9].

The main goals of this study are:

1. To do parametric analysis of flow over (National Advisory Committee for Aeronautics) NACA 0012 airfoil with plain flap at various angles of attack and flap deflected at various angles.

2. To obtain the flow properties of the airfoil with plain flap from the established theoretical relations and graphs.

3. To compare the computational results with the theoretical data and analysis the results. 
4. Provide further framework from which further research can be undertaken.

\section{ApproACH to THE PROBLEM}

The characteristics of aerodynamic flow fields are dictated by equations that represent the basic physical fundamentals. These equations are powerful enough to illustrate the fundamentals of a fluid flow. However the equations by themselves are not adequate, but must be supplemented by experimental results. Various combinations of body shapes and flow conditions need to be integrated to the results so obtained.

The governing equations of aerodynamics such as the continuity, momentum and energy equations are highly nonlinear, partial differential, or integral equations. Accurate analytical solution to these equations does not exist. CFD approach facilitates a solution to the governing equations.

\section{COMPUTATIONAL FLUID DYNAMICS}

Advent of the modern high-speed digital computer during the twentieth century has revolutionized the solution to aerodynamic problems and has given rise to a whole new discipline-Computational Fluid Dynamics (CFD)

CFD is the art of replacing the integrals or partial derivatives in the governing equations with discretized algebraic forms. These are, in turn, solved to obtain values for the flow field at discrete points in time or/and space.

Great advantage of CFD is that it can deal with completely non-linear equations of continuity, momentum and energy, without need for geometrical or physical approximations. With the advent of CFD, solutions have been found for many complex aerodynamic flow field situations which had never been solved before. For instance,

- The unsteady, viscous, turbulent, compressible, separated flow field over an airfoil at high angle of attack has no analytical solution; a solution can only be obtained by means of CFD.

- Solution to Navier-Stokes equation, applicable for varying conditions of viscosity and thermal terms is possible, without approximation, only by using CFD.

CFD solutions are entirely numerical solutions. In a CFD solution, the flow field is divided into a number of discrete points. Coordinate lines through these points generate a grid, and the discrete points are called grid points. The flow properties, such as $\mathrm{p}, \mathrm{u}, \mathrm{v}, \rho$, etc. are calculated just at the discrete grid points, and nowhere else, by means of the numerical solution of the governing flow equations. This inherent property that distinguishes CFD solutions from closed -form analytical solutions. [4]

\section{MODEL CREATION AND ANALYSIS}

The flow analysis is done using CFD tool FLUENT 6.3 along with GAMBIT 2.2.

The analysis using any CFD tool fluent 6.3 along with Gambit 2.2. Analysis consists of two phases:

1. Pre Processing
2. Solving and Post processing

The pre processing phase, using Gambit 2.2 consists of three major steps

1. Geometry creation

2. Mesh generation and quality checking

3. Boundary type specification

The post processing phase, using Fluent 6.3 consists of the following actions

a. Mesh is read, checked and scaled.

b. Type of fluid \& flow are specified.

c. Boundary conditions are chosen and Other models are enabled depending on the nature of the problem

d. Implement user designed functions and choose Discretization methods.

e. Problem is initialized and solver is started. Solution is checked for validity after convergence.

f. Required results can be obtained in the forms of vector, contour and graphical plots for further analyses.

\section{A. Model and Flow Domain Creation}

For designing the geometry of the NACA 0012 airfoil the coordinates must be known. The coordinates for the airfoil are generated using the java applet JAVA FOIL (Fig.1) [12]. The coordinates are imported into Gambit as data file (.dat) and thus the geometry is created (Fig.2).Then, grid generated over an airfoil in Gambit (Fig.3) [11].

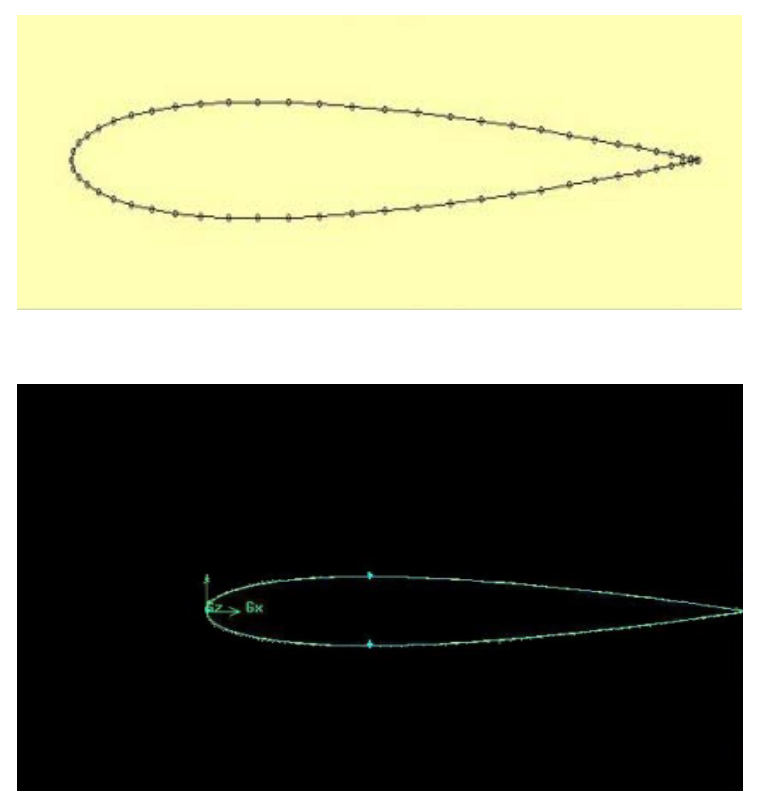

Figure 1: Java Foil with coordinates and geometry in Gambit 


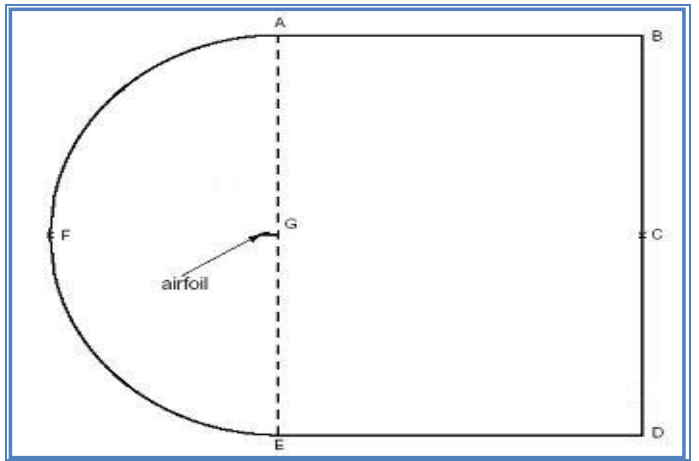

Figure 2: Geometry of Flow Domain

\section{B. D. Grid Generation and Quality Checking}

The following table provides the mesh generation technique and quality.

Table 1: Grid Properties and Quality

\begin{tabular}{|l|l|}
\hline Grid Nature & Structured \\
\hline Element & Quad \\
\hline Type & Map \\
\hline Grid Quality & \\
\hline Equiangular Skew & 0.45 \\
\hline
\end{tabular}

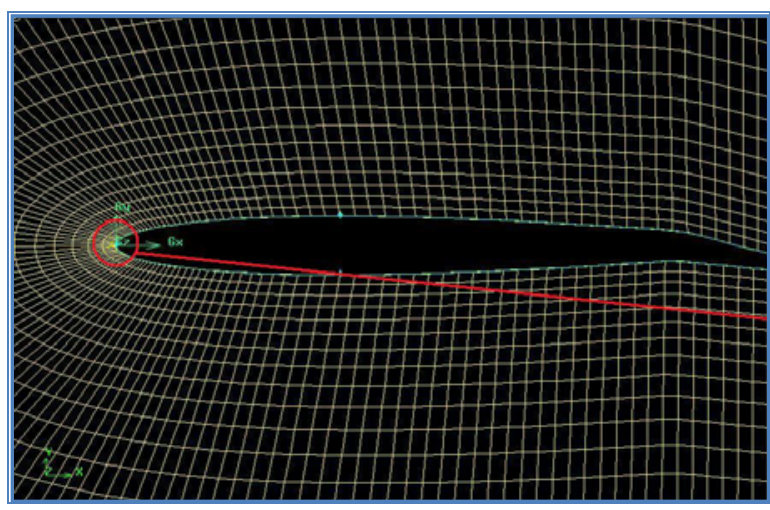

Figure 3: Grid Generation over the Airfoil

\section{Solver and Boundary Type Specification}

In this analysis FLUENT $4 / 5$ solver is chosen and the boundary type as per the figure 2 is listed below.

Table 2: Boundary Type Specification

\begin{tabular}{|l|l|l|}
\hline Edge & Boundary Type & Name \\
\hline AFE & Velocity Inlet & Inlet 1 \\
\hline AB & Velocity Inlet & Inlet 2 \\
\hline ED & Velocity Inlet & Inlet 3 \\
\hline BC & Pressure Outlet & Outlet 1 \\
\hline CD & Pressure Outlet & Outlet 2 \\
\hline Airfoil & Wall & Airfoil \\
\hline
\end{tabular}

After specifying the boundary the file is exported as mesh

\section{Analysis}

The analysis is carried out as per the parameters given in table 3.

Table 3: Analysis Parameters

\begin{tabular}{|c|c|}
\hline Parameter & Value \\
\hline Fluent Version & $2 \mathrm{ddp}$ \\
\hline Solver & Pressure based \\
\hline Time & Steady \\
\hline Formulation & Implicit \\
\hline Viscous Model & k-epsilon \\
\hline \multicolumn{2}{|c|}{ Materials } \\
\hline Material type & Fluid \\
\hline Fluid material & Air \\
\hline Density & $1.225 \mathrm{~kg} / \mathrm{m} 3$ \\
\hline Viscosity & $1.7847-\mathrm{e} 05 \mathrm{~kg} / \mathrm{m}-\mathrm{s}$ \\
\hline \multicolumn{2}{|c|}{ Boundary conditions } \\
\hline Zone & Inlet 1 \\
\hline Type & Velocity inlet \\
\hline \multicolumn{2}{|c|}{ Velocity inlet } \\
\hline Velocity specification method & Components \\
\hline $\mathrm{X}$-velocity & as per angle of attack \\
\hline Y-velocity & as per angle of attack \\
\hline Turbulence specification method & $\mathrm{K}$ and epsilon \\
\hline Turbulence Kinetic energy & 1 \\
\hline Turbulence Dissipation rate & 1 \\
\hline \multicolumn{2}{|c|}{ Boundary conditions same for inlet $2 \& 3$} \\
\hline \multicolumn{2}{|c|}{ Solution controls } \\
\hline Pressure-velocity coupling & PRESTO \\
\hline Momentum & Second order upwind \\
\hline Turbulence Kinetic energy & Second order upwind \\
\hline Turbulence Dissipation rate & Second order upwind \\
\hline \multicolumn{2}{|c|}{ Solution initialization } \\
\hline Compute from & Inlet 1 \\
\hline \multicolumn{2}{|c|}{ Residual monitors } \\
\hline Convergence Criterion & $1.00 \mathrm{E}-06$ \\
\hline \multicolumn{2}{|c|}{ Force Monitors } \\
\hline Coefficient & Lift, Drag \\
\hline Wall zone & Airfoil \\
\hline Force vector $\mathrm{X}$ & as per angle of attack \\
\hline Force vector Y & as per angle of attack \\
\hline
\end{tabular}
file. 


\section{RESULTS AND DISCUSSIONS}

The results yielded by the CFD analysis are represented as graphs and tables in this section.

\section{A. The CP Plot}

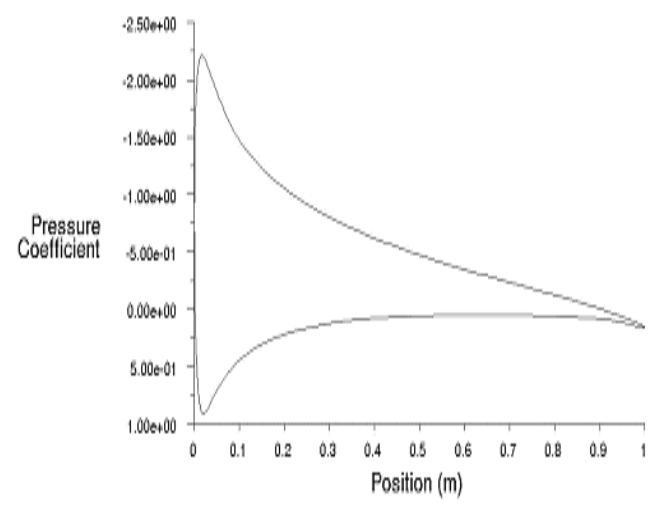

Figure 4: Cp Distribution over NACA $0012 @$ AOA=8 deg

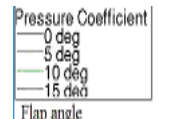

Flap angle

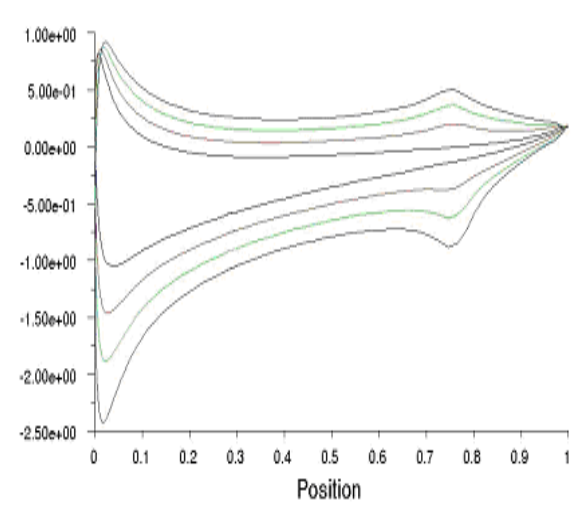

Figure 5: Cp Distribution over NACA 0012 with Plain Flap Deflected at Various Angles $(\delta=5,10,15 \mathrm{deg})$

The pressure distribution over NACA 0012 at an Angle of Attack $(\mathrm{AOA})=8 \mathrm{deg}$ is presented in fig. 4 and from the plot it is clear that, the pressure distribution over the airfoil increases when AOA increases. Thus, the lift force generated by the airfoil also increases.

The pressure distribution over NACA 0012 with different plain flap deflection angles $(\delta=5,10,15 \mathrm{deg})$ is presented in fig.5 and from the plot it is clear that, as the flap gets deflected the pressure distribution over the airfoil increases thus the lift force generated by the airfoil also increases. Therefore, by increasing both AOA of the airfoil and deflection angle of the flap, we can produce more lift with the help of high lift device plain flaps.

\section{B. The Pressure Contour}

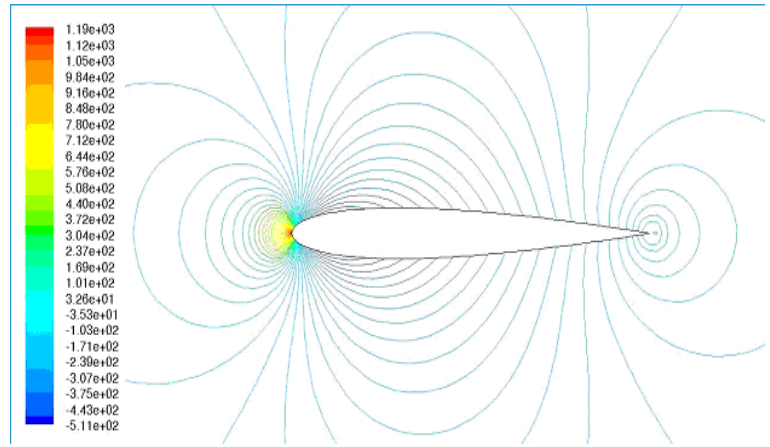

Figure 6: Pressure Contour over NACA 0012 with neutral flap (a) $\mathrm{AOA}=0 \mathrm{deg}$

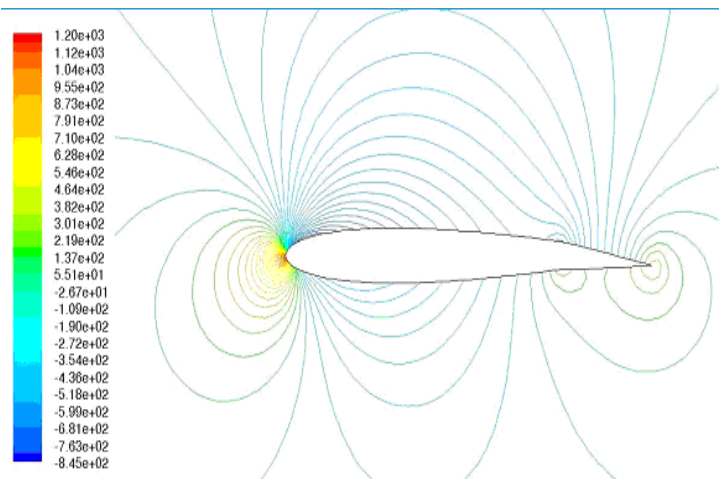

Figure 7: Pressure Contour over NACA 0012 with flap angle 5 deg @ $\mathrm{AOA}=0 \operatorname{deg}$

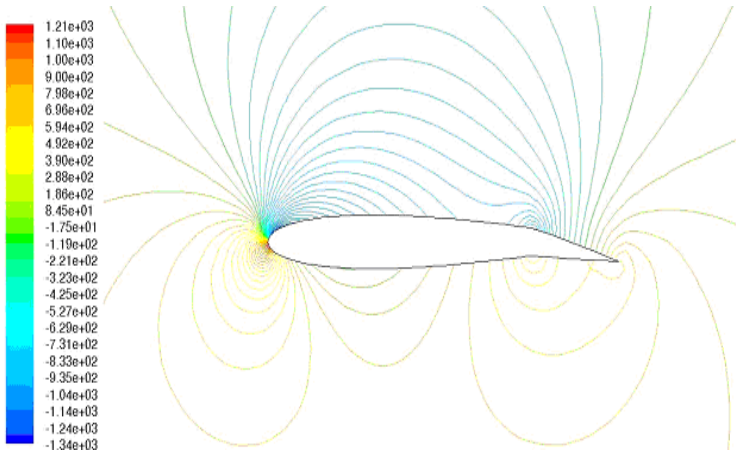

Figure 8: Pressure Contour over NACA 0012 with Flap Angle $10 \operatorname{deg} @ \mathrm{AOA}=0 \mathrm{deg}$

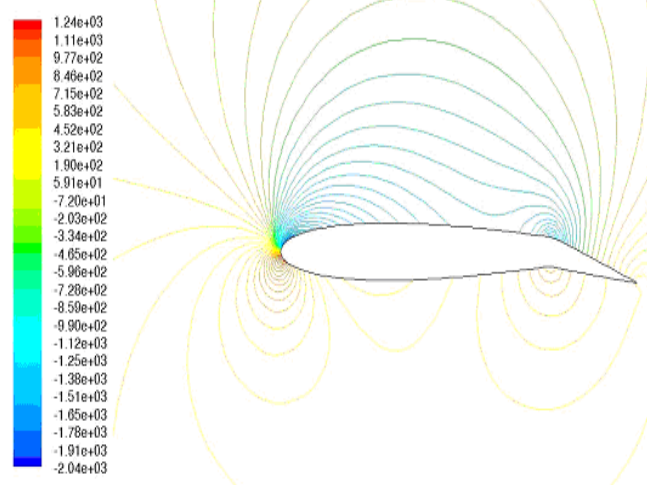

Figure 9: Pressure Contour over NACA 0012 with Flap Angle $15 \operatorname{deg} @ \mathrm{AOA}=0 \mathrm{deg}$ 
The pressure contour over NACA 0012 with different plain flap deflection angles $(\delta=0,5,10,15 \mathrm{deg})$ at zero angle of attack of the airfoil is presented in the figures 6 to 9 and from the plots it is clear that, as the flap gets deflected the pressure distribution over the airfoil increases thus the lift over an airfoil also increases. Therefore, by increasing deflection angle of the flap, even without changing the AOA of the airfoil, we can increase the lift over an airfoil.

\section{Variation of $C L$ and $C D$ with $\alpha$ and $\delta$}

The following plot (fig 10) shows the variation of coefficient of lift $\left(\mathrm{C}_{\mathrm{L}}\right)$ with varying AOA and flap angle. The variation of lift coefficient with $\alpha$ and $\delta$ is presented in table 4 and the corresponding values of $\mathrm{C}_{D}$ are provided in Table 5 .

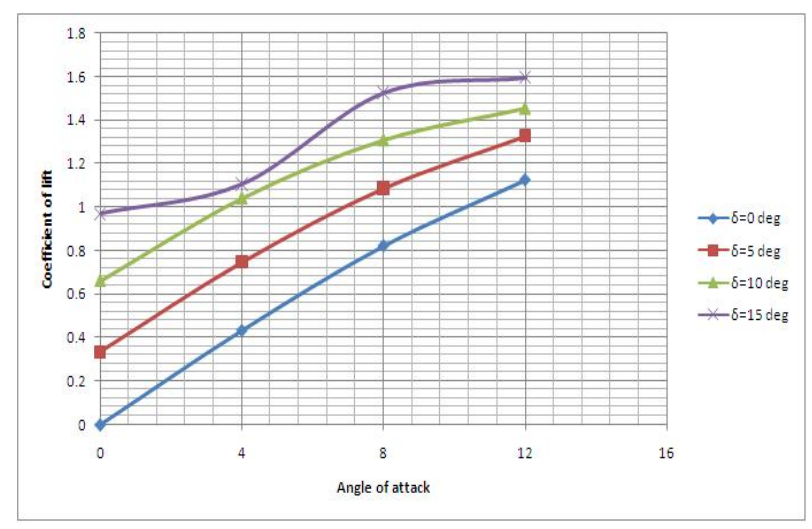

Figure 10: $\mathrm{C}_{\mathrm{L}}$ Vs AOA for Various Flap Angles

Table 1: Variation of $\mathrm{C}_{\mathrm{L}}$ with $\alpha$ and $\delta$

\begin{tabular}{|l|l|l|l|l|}
\hline AOA & $\delta=0 \mathrm{deg}$ & $\delta=5 \mathrm{deg}$ & $\delta=10 \mathrm{deg}$ & $\delta=15 \mathrm{deg}$ \\
\hline 0 & 0 & 0.335 & 0.661 & 0.9701 \\
\hline 4 & 0.434 & 0.747 & 1.041 & 1.1062 \\
\hline 8 & 0.823 & 1.0869 & 1.3087 & 1.5269 \\
\hline 12 & 1.126 & 1.327 & 1.454 & 1.596 \\
\hline
\end{tabular}

Table 2 Variation of $C_{D}$ with $\alpha$ and $\delta$

\begin{tabular}{|l|l|l|l|l|}
\hline AOA & $\delta=0 \mathrm{deg}$ & $\delta=5 \mathrm{deg}$ & $\delta=10 \mathrm{deg}$ & $\delta=15 \mathrm{deg}$ \\
\hline 0 & 0.011 & 0.013 & 0.0163 & 0.0213 \\
\hline 4 & 0.016 & 0.0205 & 0.0278 & 0.036 \\
\hline 8 & 0.028 & 0.0378 & 0.0494 & 0.0619 \\
\hline 12 & 0.054 & 0.0696 & 0.089 & 0.1072 \\
\hline
\end{tabular}

The variation of coefficient of lift with varying AOA and flap angle is presented in Fig.10 and it is clearly suggest that, the increment of lift can be achieved through increasing AOA and flap angles. The increment of lift value for different angles has been presented in table 4 and it clearly shows that, upto the AOA of $12 \mathrm{deg}$, the lift increases for increasing flap deflection angle but beyond AOA of 12 deg, it will leads to stall so it is undesirable for any aircraft .Similarly the variation of Drag Coefficient $\left(C_{D}\right)$ with $\alpha$ and $\delta$ is presented in table 5 and it is showing that, we can not get the lift for free of cost, the drag coefficient is the price for lift.

\section{Increment in Lift Due to Flap Deflection ( $\triangle C L)$}

The most important result of the analysis is the increment due to flap deflection.

Table 3 Increment in $\mathrm{C}_{\mathrm{L}}$ due to Flap Deflection

\begin{tabular}{|l|l|l|}
$\delta$ & $\Delta \mathrm{C}_{\mathrm{L}}$ (Computational) & $\begin{array}{l}\Delta \mathrm{C}_{\mathrm{L}} \\
\text { (Analytical) }\end{array}$ \\
\hline 5 & 0.335 & 0.3502185 \\
\hline 10 & 0.661 & 0.684335 \\
\hline 15 & 0.9701 & 0.9942985 \\
\hline
\end{tabular}

The increment in lift due to flap deflection is presented in table 6 and it clearly shows that the lift increases as flap deflection angle increases. The computational results has been compared with the analytical value and the results are found to be within acceptable limits

\section{E. Discussions}

From the analysis of above results the following statements are inferred.

Fig 7 shows that the pressure distribution over the airfoil increases when the flap is deflected. From the plot it's clear that as the flap gets deflected the pressure distribution over the airfoil increases thus the lift force generated by the airfoil also increases.

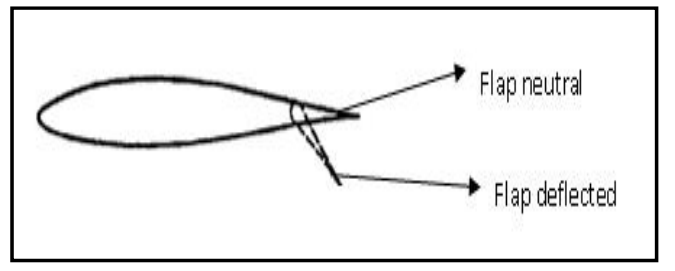

Figure 11: Geometry of plain Flap

The pressure distribution is clearly figured in the pressure contours in fig 6-9.

The main effect produced by flap deflection is an increase in the effective camber of the wing; this reduces the zero lift incidences, without affecting the lift curve slope. Thus at incidences well below the stall, there is a constant increase in lift coefficient. The effect may be slightly enhanced because flap deflection additionally produces a slight increase ineffective incidence. A further effect is however is to hasten the onset of the stall, because separations tend to occur early over the rear of the flap, where the airfoil is in effect so highly cambered [6] and [7]

The increment in the lift coefficient has been tabulated in Table 6 and expressed as a plot between $\mathrm{C}_{\mathrm{L}}$ and $\alpha$ in fig 10 . Table 6 also provides a comparison between the computational and analytical values of increment of lift coefficient. For any analysis, the computational and analytical results should match very closer, hence, in this analysis, increment in lift due to flap deflection of both computational and analytical results are found to be well within limits.

\section{F. Analytical Solution for Increment in Lift Coefficient}

The increment in lift coefficient is given by 


$$
\Delta C_{L}=\left(\delta_{f}\right)\left(\frac{C_{L \delta}}{C_{L \delta \text { theory }}}\right)\left(C_{L \delta \text { theory }}\right) k^{\prime}
$$

Where $\mathrm{K}^{\prime}$ - is a correction factor which accounts for nonlinearities due to high flap deflection. (Refer fig 12)

$\left(\mathrm{C}_{\mathrm{L} \delta}\right)_{\text {theory }}$ is found from fig 13. It accounts for flap size and thickness ratio. [1] and [2]

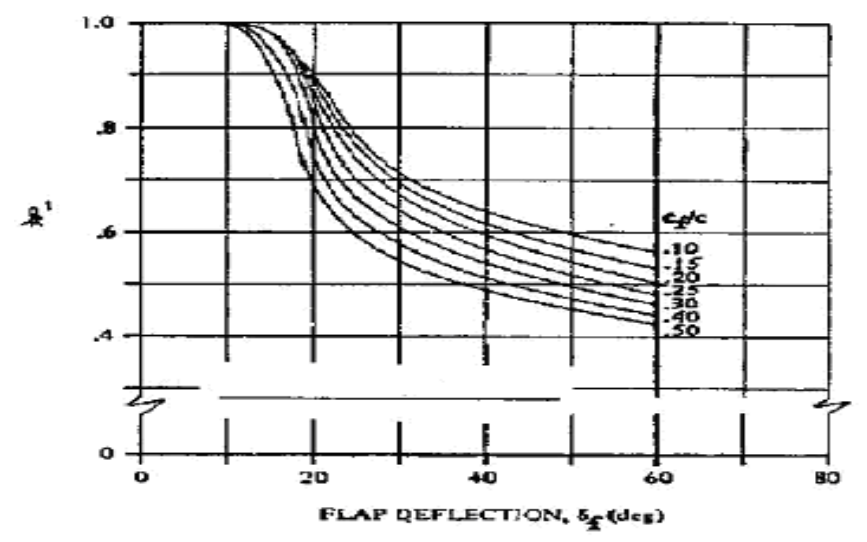

Figure 12: Correction Factor vs. Flap Deflection

$\mathrm{C}_{\mathrm{L} \delta} /\left(\mathrm{C}_{\mathrm{L} \delta}\right)$ theory is found from fig $14,\left(\delta_{\mathrm{f}}\right)$ is the flap deflection in rad. The analytical results obtained from above equation and references are listed in Table 6.

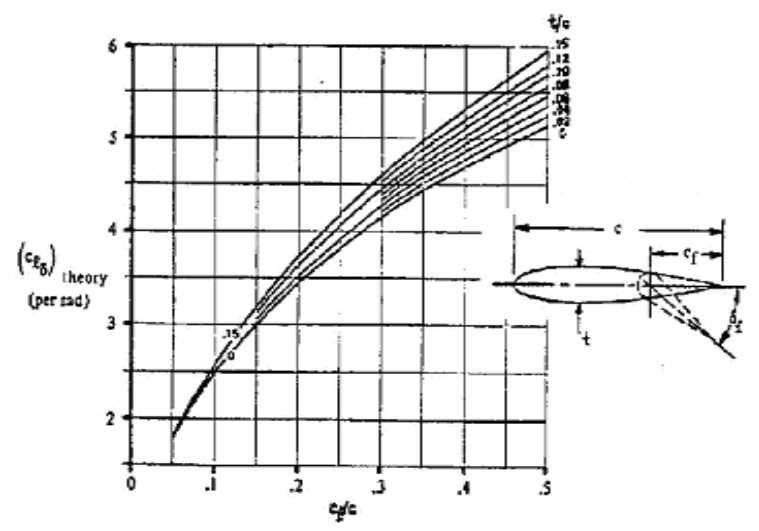

Figure 13: $\left(\mathrm{C}_{\mathrm{L} \delta}\right)$ theory vs. $\mathrm{c}_{\mathrm{f}} / \mathrm{c}$

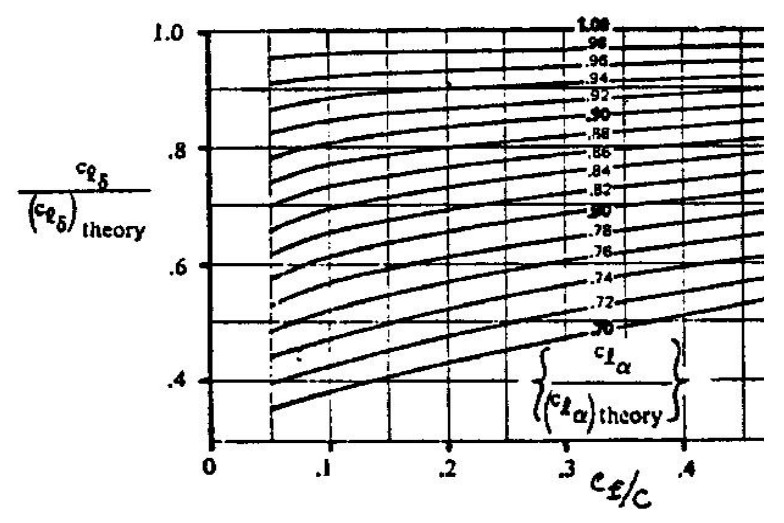

Figure 14: $\mathrm{C}_{\mathrm{L} \delta} /\left(\mathrm{C}_{\mathrm{L} \delta}\right)$ theory vs. $\mathrm{C}_{\mathrm{f}} / \mathrm{C}$

\section{G. Calculation}

$$
\Delta C_{L}=\left(\delta_{f}\right)\left(\frac{C_{L \delta}}{C_{L \delta \text { theory }}}\right)\left(C_{L \delta \text { theory }}\right) k^{\prime}
$$

Consider NACA 0012 airfoil with unit chord length $\left(\mathrm{t}=12 \%\right.$ of chord) and Plain flap of flap chord $\left(\mathrm{C}_{\mathrm{f}}\right) 25 \%$ of chord(C).

The value of $C_{L \alpha} /\left(C_{L \alpha}\right)$ theory for NACA 0012 airfoil is $0.98\left[\mathrm{C}_{\mathrm{L} \alpha}\right.$-lift curve slope]. [5]

$\mathrm{C}_{\mathrm{f}} / \mathrm{C}=0.25$

$\mathrm{t} / \mathrm{c}=0.12$

Let Flap angle $\left(\delta_{\mathrm{f}}\right)=5 \mathrm{deg}(0.087 \mathrm{rad})$

From fig $12, \mathrm{k}^{\prime}=1$

From fig $13,\left(\mathrm{C}_{\mathrm{L} \delta}\right)$ theory $[$ per rad] $=4.15$

From fig $14, \mathrm{C}_{\mathrm{L} \delta} /\left(\mathrm{C}_{\mathrm{L} \delta}\right)$ theory $=0.97$

$\Delta \mathrm{C}_{\mathrm{L}}=(0.087) *(0.97) *(4.15) *(1)=0.350218$

\section{CONCLUSION}

The effect of the high lift devices and their characteristics were evidently notable from the plain flap analysis. The importance of lift characteristics during STOL (Short Take Off and Landing) is a key matter of discussion in recent times. The results of the computational approach prove its reliability and have a great extent [10]. Camber of the wing has been increased to enhance the lift by flap deflection. The objectives of this analysis were successfully completed by making that at incidences well below the stall, there is a constant increase in lift coefficient. Thus the results obtained from the analysis are compared with analytical solutions to establish the influence and relevance of flap as an effective high lift device.

\section{REFERENCES}

[1] A. Abbott, Ira and E. Von Duenhoff, Albert, Theory of wing sections, Dover publications, 1959.

[2] D. Anderson, John, Jr.: Fundamentals of Aerodynamics, $4^{\text {th }}$ ed., Tata McGraw-Hill Publishing Company Ltd.

[3] D. Anderson, John, Jr.: Introduction to Flight $5^{\text {th }}$ ed., Tata McGraw-Hill Publishing Company Ltd

[4] D. Anderson, John, Jr.: Computational Fluid Dynamics: The basics with Applications, $4^{\text {th }}$ ed., Tata McGraw-Hill Publishing Company Ltd.

[5] J. Roskam, Airplane Design: Part IV, Preliminary Calculation of Aerodynamic Characteristics of Thrust and Power, Roskam Engineering and Aviation Corporation.

[6] A.V. Petrov, Aerodynamics of STOL aircraft with wings blowing by turbofan exhaust jets and propfan slipstreams. AIAA International Powered Lift Conference, Santa Clara, USA, AIAA-93-4832, 1993.

[7] A.V. Petrov, Aerodynamics of aircraft with wing-powered lift systems. AIAA International Powered Lift Conference, Santa Clara, USA, AIAA93-4836, 1993.

[8] A.V. Petrov, Wing powered high-lift methods. Moscow. FIZMATLIT, Pp.404, 2011

[9] A.V. Petrov, V.K. Svjatodukh, V.A. Tuntsev, N. Chernavskikh Ju. The problems of creation of transport short takeoff and landing aircraft. Aviation science and technology, Vol. LXXVII, №3 (662), Pp.1-7, 2003. 
[10] A.V. Petrov, V.D. Bokser, G.G. Sudakov and P.V. Savin, Application of tangential jet blowing for suppression of shock-induced flow separation at transonic speeds. 27-th Congress of the ICAS, Nice, France, 2010.

[11] http://www.fluent.com/software/sf_mesh_and_tutorials/tutorial_airfoil.h tm

[12] http://www.mh-aerotools.de/airfoils/jf_applet.htm

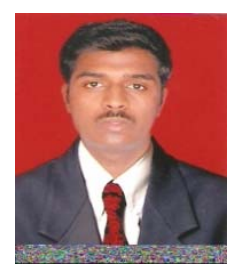

M. Senthil Kumar, Author has completed his B.Tech in Mechanical Engineering from Pondicherry Engineering College, Pondicherry and M.E in Aeronautical Engineering from Park College of Engineering and Technology, Coimbatore respectively in 2005 and 2007. $\mathrm{He}$ is now pursuing his $\mathrm{PhD}$ from Coimbatore Institute of Technology, Anna University-Chennai. He has six years of teaching and research experience in Kumaraguru College of Technology, Coimbatore and currently he holds the post of Assistant professor in the Department of Aeronautical Engineering, Kumaraguru College of Technology, Coimbatore, TamilNadu, India. His email id is mgskumar_pec@yahoo.com.

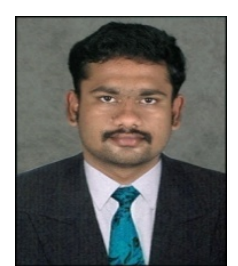

K. Naveen Kumar, Author has completed his B.Tech in Aeronautical Engineering from Park college of Engineering and Technology, Coimbatore and M.E in Aeronautical Engineering from Anna University of Technology, Tirunelveli respectively in 2010 and 2012.He has a year of teaching and research experience in Kumaraguru College of Technology, Coimbatore and currently he holds the post of Assistant professor in the Department of Aeronautical Engineering, Kumaraguru College of Technology, Coimbatore, TamilNadu, India. His email id is naveenaero.1@gmail.com. 